\title{
Asthma symptoms, mannitol reactivity and exercise-induced bronchoconstriction in adolescent swimmers versus tennis players
}

This article was published in the following Dove Press journal:

Journal of Asthma and Allergy

3 October 2017

Number of times this article has been viewed

\section{Kerstin Romberg ${ }^{1,2}$ \\ Ellen Tufvesson' \\ Leif Bjermer'}

'Respiratory Medicine and Allergology, Department of Clinical Sciences, Lund, Lund University, Lund, ${ }^{2}$ Health Care Center, Näsets Läkargrupp, Höllviken, Sweden
Correspondence: Kerstin Romberg Respiratory Medicine and Allergology, Department of Clinical Sciences, Lund, Lund University, 22, I85 Lund, Sweden

$\mathrm{Tel}+46708470514$

Email kro@nlg.nu
Background: Strenuous physical activity at an elite level is associated with an increased risk for asthma and, in some sports, also prevalence of allergies. The aim of this study was to investigate the prevalence of asthma and allergy among elite swimmers and tennis players and compare airway hyperreactivity to mannitol and exercise.

Materials and methods: One hundred and one adolescent swimmers and 86 tennis players answered a questionnaire about respiratory symptoms and allergy and performed mannitol challenge and sport-specific exercise challenge. Atopy was assessed and fractional exhaled nitric oxide was measured. Mannitol positivity was defined as drop in $\mathrm{FEV}_{1} \geq 15 \%$ (ordinary criteria) and/or $\beta_{2}$-reversibility $(\geq 15 \%)$ after provocation (extended criteria). A positive exercise test was defined as a drop in $\mathrm{FEV}_{1} \geq 10 \%$ (ordinary criteria) and/or $\beta_{2}$-reversibility ( $\geq 15 \%$ ) after provocation (extended criteria). Club cell protein (CC16) was measured in urine before and after the challenges. Results: Asthma symptoms were common in both groups. More swimmers had exercise-induced symptoms ( $77 \%$ versus $50 \%$ ) and current asthma symptoms ( $56 \%$ versus $38 \%$ ), compared to the tennis players. More swimmers also had a positive mannitol challenge test both using ordinary ( $26 \%$ versus $6 \%$ ) and extended criteria ( $43 \%$ versus $17 \%$ ), while the number of positive exercise tests did not differ. After exercise (but not mannitol) challenge, CC16 level was increased in both groups, but to a higher extent in tennis players. There were no differences in atopy, rhinitis or fractional exhaled nitric oxide.

Conclusion: We found a high prevalence of asthma among elite swimmers and tennis players and a higher frequency of current asthma and positive mannitol challenge tests among the swimmers. This indicates an unfavorable exercise environment.

Keywords: asthma, sport, swimming, tennis, mannitol, exercise, CC16 bronchial hyperreactivity, bronchial hyperreactivity test

\section{Introduction}

Elite level sport activities result in an increased risk of asthma and allergic rhinitis independent of the sport practiced. ${ }^{1,2}$ The frequency, however, is intimately related to both the type of sport and its environmental factors. ${ }^{2}$ There is a problem with both an over- and under-diagnosis of asthma among young athletes. The diagnosis of asthma in athletes is often difficult, and the use of indirect tests has been recommended since indirect provocation tests better reflect present airway inflammation. Exercise challenge test has earlier been shown to identify exercise-induced asthmatic patients who benefit from anti-inflammatory treatment. ${ }^{3,4}$ An alternative indirect test, mannitol challenge, has been proposed to confirm the presence of exercise-induced bronchoconstriction. 
Mannitol reactivity correlates fairly well to other osmotic stimuli such as exercise, dry air hyperventilation and hypertonic saline in active asthmatics. ${ }^{5}$

Swimming represents a significant risk for asthma development, ${ }^{6}$ and a large number of swimmers develop increased airway hyperreactivity to histamine. ${ }^{7,8}$ We have previously reported an increased prevalence of asthma symptoms in aspiring elite swimmers. ${ }^{6}$ These subjects also had a high prevalence of positive exercise challenge and mannitol challenge test. ${ }^{9}$ Another finding was the increased concentration of club Cell protein (CC16) in urine after exercise, but not after mannitol challenge. ${ }^{10} \mathrm{CC} 16$, secreted by club cells found primarily in the respiratory bronchioles, is assumed to have a protective role against airway inflammation. ${ }^{11,12}$ We believe there is a link between chloramine exposure and disturbances of the peripheral airways, resulting in an effective secretion of $\mathrm{CC} 16$.

Asthma in athletes of different sports may have a different pathophysiology. ${ }^{13,14}$ While swimming is known to be a risk factor for asthma development, much less is known about tennis, despite a high frequency of respiratory symptoms reported. ${ }^{15}$ Even though tennis is not defined as an endurance sport, there is a major element of endurance in the sport, particularly during long matches. The tennis-specific environment is mainly an indoor sport activity in our northern latitudes, except during the summer months.

The aim of this study was to compare the elite aspiring swimmers and tennis players to investigate their association to asthma and exercise-induced bronchoconstriction. The second aim was to explore the difference in symptoms and allergic sensitizations, as well as results in mannitol challenge and sportspecific exercise challenge test. We also wanted to explore the pathophysiologic mechanisms by analyzing the urinary levels of $\mathrm{CC} 16$, leukotriene $\mathrm{E}_{4}\left(\mathrm{LTE}_{4}\right)$ and 11 $\beta$-prostaglandin- $\mathrm{F}_{2 \alpha}$ $\left(11 \beta-\mathrm{PGF}_{2 \alpha}\right)$ before and after the provocation tests.

\section{Materials and methods Subjects}

A total of 101 swimmers and 86 tennis players from elite training groups participated in the study (Supplementary material).

As a reference group, all the pupils of age 13-20 in the community of Vellinge $(\mathrm{n}=1628)$ were included.

\section{Study design}

The athletes were tested at two different occasions, at least 1 week apart. On the first day, the subjects answered a questionnaire, had a physical examination, a skin prick test and a measurement of fractional exhaled nitric oxide $\left(\mathrm{F}_{\mathrm{E}} \mathrm{NO}\right.$, Supplementary material). All swimmers and 79 (92\%) tennis players underwent a mannitol challenge test, and 97 (96\%) swimmers and 67 (78\%) tennis players underwent the exercise challenge test. The mannitol challenge was performed on the first occasion and the sport-specific exercise challenge test on the second occasion (except for three tennis players who underwent the tests in reverse order due to their competition schedule). Urine samples were collected before and 1 hour after each provocation test (for analyses of CC16, $\mathrm{LTE}_{4}$ and $11 \beta-\mathrm{PGF}_{2 \alpha}$, Supplementary material). No asthma medication was taken on the days of the tests, and short- and long-acting $\beta 2$-agonists were not taken for at least 24 hours. None of the subjects were on regular antihistamines at the time of the study.

The reference group answered the questionnaire on one of two possible occasions.

The trichloramine content of the air in the swimming pool facilities where the swimmers had their regular training was measured on two different occasions (Supplementary material).

\section{Questionnaire}

The questions were about presence of respiratory symptoms, allergic symptoms and lifestyle factors, as previously described. ${ }^{6}$ The questionnaire was filled in by the subjects and complemented by an interview and physical examination by a study responsible physician. Doctor's diagnosis of asthma was done according to Gina guidelines ${ }^{16}$ prior to the study by either a specialist or a general practitioner.

"Current asthma symptoms" were defined as report of symptoms such as wheezing and/or nocturnal symptoms without respiratory infection and/or asthma medication during the past 12 months.

"Current asthma with exercise-induced symptoms" was defined as current asthma symptoms with wheezing, coughing and/or chest tightness adjacent to physical activity.

"Current asthma with hyperreactive symptoms" was defined as current asthma symptoms with wheezing, coughing and/or chest tightness adjacent to contact with irritants.

"Current allergic asthma" was defined as current asthma symptoms with wheezing, coughing and/or chest tightness adjacent to contact with airborne allergens.

"Exacerbations" were defined as either emergency room visits, sick leave due to asthma or periods with more accentuated symptoms that required an increase in medication.

"Current rhinitis" was defined as report of symptoms such as sneezing, runny or blocked nose without concomitant respiratory infection during the past 12 months.

"Rhinitis with impact on daily living" was defined as a current rhinitis that affected the swimmers in their daily lives. 
The swimmers and the tennis players completed the questionnaire in their training center and the reference group subjects completed the questionnaire in their classroom.

\section{Mannitol challenge test}

The mannitol challenge tests were performed (Supplementary material) at site for the sport activities. A positive test according to ordinary criteria was defined as a drop in FEV of $\geq 15 \%$ compared to baseline. PD $15_{\text {Mann }}$ was defined as the cumulative dose of mannitol giving a $15 \%$ fall in $\mathrm{FEV}_{1}$. Postchallenge $\mathrm{FEV}_{1}$ was measured after 30 minutes. Thereafter, all the athletes were administered terbutaline $(1 \mathrm{mg})$ by inhalation, followed by a new spirometry performed after another 30 minutes. Reversibility was defined as an improvement in $\mathrm{FEV}_{1}$ by $>15 \%$ after terbutaline inhalation from the maximum fall in $\mathrm{FEV}_{1}$. A positive test according to extended criteria was defined as positive ordinary criteria and/or reversibility. ${ }^{9}$

\section{Sport-specific exercise challenge test}

In the exercise test for the swimmers, both males and females swam (crawled) $600 \mathrm{~m}$ during 6-8 minutes. During the first 2 minutes, they exercised at a pulse rate of maximum 150, in order to avoid lactate accumulation. Thereafter, they finished the lap during the next 4-6 minutes, aiming to achieve a pulse rate of $>90 \%$ of the maximal capacity ( $220 \mathrm{bpm}-$ age in years) based on recommendation for exercise testing. ${ }^{17}$

In the exercise test for the tennis players, all participants ran for 6 minutes on the tennis court, mimicking the movements in tennis. The tennis players ran on one half of the tennis court from the center and out to the corners. Each time they passed the center or one of the corners, they simulated a tennis stroke. The first 2 minutes' target pulse was 150 and during the last 4 minutes, they were aiming for $\geq 90 \%$ of the maximal capacity ( $220 \mathrm{bpm}-$ age in years).

For both the swimmers and the tennis players, the pulse rate was checked during the race by a Polar water-proof pulse watch (Polar RS 400), and the swimmers were checked manually every $100 \mathrm{~m}$ and the tennis players each minute.

Flow volume spirometry was performed before the start, immediately after finishing the lap (about 2 minutes after the exercise), and then at 5, 10, 15 and 30 minutes after the race. The subjects then inhaled $1 \mathrm{mg}$ terbutaline and a new spirometry was performed after another 30 minutes. A positive test according to ordinary criteria was defined as a drop in $\mathrm{FEV}_{1}$ of $\geq 10 \%$ from the baseline. Reversibility was defined as an improvement in $\mathrm{FEV}_{1}$ by $\geq 15 \%$ after terbutaline inhalation, compared to maximum fall in $\mathrm{FEV}_{1}$. A positive test according to extended criteria was defined as positive ordinary criteria and/or reversibility.

\section{Statistical analysis}

SPSS version 21 (IBM Corporation, Armonk, NY, USA) was used for statistical analysis. All data are given as median and interquartile range, unless otherwise stated. Pearson's chi-square test, Fisher's exact test and Mann-Whitney $U$ test were used for group comparisons. Spearman's test was used for correlation analyses. A $p$ value of $<0.05$ (two-tailed) was considered significant.

The study was approved by the Regional Ethical Review Board in Lund, Sweden 87/2007 and 357/2008, and all participants and/or parents gave written informed consent.

\section{Results Study population}

There was no significant difference regarding distribution of sex or age among the three groups. Both swimmers and tennis players had good basal lung function (forced vital capacity and $\mathrm{FEV}_{1}$ above $100 \%$ of the reference value ${ }^{18}$ ) and it was even higher in the swimmers. There was no difference in positive skin prick tests or $\mathrm{F}_{\mathrm{E}} \mathrm{NO}$ between the swimmers and the tennis players (Table 1). In both the swimming and tennis playing groups, those with atopy had significantly higher $\mathrm{F}_{\mathrm{E}} \mathrm{NO}$ values, both regarding median $\mathrm{F}_{\mathrm{E}} \mathrm{NO}$ value $(p=0.021)$ and number of individuals with $\mathrm{F}_{\mathrm{E}} \mathrm{NO} \geq 20(p=0.02)$.

\section{Doctor-diagnosed asthma}

A higher proportion of the swimmers had doctor-diagnosed asthma compared to the tennis players, but the difference was not significant. A similar pattern was seen in tennis players compared to the reference group $(p=0.058)$. No significant difference in using any kind of asthma medication was seen, but the regular use of inhaled corticosteroids was significantly higher among the swimmers (Table 1).

\section{Respiratory symptoms and allergies}

Respiratory symptoms; swimmers, tennis players and the reference group

The swimmers had a significantly higher frequency of exercise-induced symptoms $(p<0.0001)$, current asthma symptoms $(p=0.005)$, current asthma symptoms during exercise $(p<0.001)$ and asthmatic symptoms in contact with irritants $(p=0.013)$, compared to the tennis players. In comparison with the reference group, the swimmers had a significantly higher frequency of exercise-induced symptoms 
Table I Study population

\begin{tabular}{|c|c|c|c|c|c|c|c|}
\hline & \multicolumn{2}{|c|}{ Reference group, $n=\mid 626$} & \multicolumn{2}{|c|}{ Swimmers, $n=101$} & \multicolumn{2}{|c|}{ Tennis players, $n=86$} & \multirow[t]{2}{*}{ p-value* } \\
\hline & $\mathbf{n}$ & $\%$ & $\mathbf{n}$ & $\%$ & $\mathbf{n}$ & $\%$ & \\
\hline Male/female & $828 / 798$ & $51 / 49$ & $55 / 46$ & $55 / 46$ & $54 / 32$ & $63 / 37$ & N.S. \\
\hline Age, years ${ }^{a}$ & 16 & $15-17$ & 16 & $14-17$ & 16 & $15-18$ & N.S. \\
\hline Training $>6$ years & 514 & 31.6 & 88 & 87.1 & 75 & 87.2 & N.S. \\
\hline Weekly training, hours ${ }^{\mathrm{a}}$ & 4 & $0-7$ & 18 & $15-20$ & 12 & $11-15$ & $<0.0001$ \\
\hline Doctor-diagnosed asthma & 275 & 16.9 & 37 & 36.6 & 21 & 25.0 & 0.089 \\
\hline Any asthma medication & 205 & 12.6 & 31 & 30.7 & 18 & 21.4 & N.S. \\
\hline $\begin{array}{l}\text { Regular inhalation of } \\
\text { corticosteroids }\end{array}$ & 79 & 4.9 & 17 & 16.8 & 5 & 6.0 & 0.023 \\
\hline Eczema ever & 678 & 41.7 & 57 & 56.4 & 28 & 33.3 & 0.002 \\
\hline FVC, \% predicted ${ }^{\mathrm{a}}$ & n.a. & n.a. & 116 & $109-122$ & 105 & $96-111$ & $<0.0001$ \\
\hline $\mathrm{FEV}_{\mathrm{l}}, \%$ predicted ${ }^{\mathrm{a}}$ & n.a. & n.a. & 112 & $104-118$ & 104 & $96-112$ & $<0.0001$ \\
\hline Atopy (positive skin prick test) & n.a. & n.a. & 54 & 53.5 & 38 & 46.9 & N.S. \\
\hline $\mathrm{F}_{\mathrm{E}} \mathrm{NO}, \mathrm{ppb}^{\mathrm{a}}$ & n.a. & n.a. & 13 & $9-18$ & 14 & $11-18$ & N.S \\
\hline $\mathrm{F}_{\mathrm{E}} \mathrm{NO} \geq 20 \mathrm{ppb}$ & n.a. & n.a. & 21 & 20.8 & 15 & 18.5 & N.S. \\
\hline
\end{tabular}

Notes: Descriptive data from elite aspiring swimmers and tennis players. ${ }^{p} p=$ statistical significance between swimmers and tennis players with Pearson's chi-square test. Median and IQR.

Abbreviations: $\mathrm{F}_{\mathrm{E}} \mathrm{NO}$, fractional exhaled nitric oxide; FVC, forced vital capacity; IQR, interquartile range; n.a., not applicable; N.S., not significant.

$(p<0.0001)$ and current asthma symptoms, independent of whether the symptoms were triggered by exercise $(\mathrm{p}<0.0001)$, irritants $(p<0.0001)$ or allergens $(\mathrm{p}=0.001)$, compared to the reference group, as previously described. ${ }^{6}$ We also found that tennis players had significantly more exercise-induced symptoms $(p<0.0001)$, current asthma symptoms during exercise $(p=0.005)$ and current asthma symptoms $(p=0.040)$, compared with the reference group (Figure 1).

\section{Airway hyperreactivity tests}

The frequency of positive mannitol challenge was significantly higher for the swimmers, using both ordinary and extended criteria. In contrast, there was no significant difference in positive exercise challenge test between the groups, using either ordinary or extended criteria (Table 2).

The frequency of having any positive test (either mannitol challenge and/or exercise challenge) was significantly higher for the swimmers compared to the tennis players, using extended (but not ordinary) criteria. In addition, the swimmers were significantly more reversible after provocation in both provocation tests (Table 2).

There was a wide variation in PD15 ${ }_{\text {Mann }}$ among the athletes, with the subjects subcategorized into mild (>155 mg), moderate $(>35-\leq 155 \mathrm{mg}$ ) or severe $(\leq 35 \mathrm{mg})$ airway hyperreactivity ${ }^{19}$ to mannitol (Figure 2 ).

We found discrepancies between specificity and sensitivity in relation to hyperreactivity in both the mannitol (Figure 3) and exercise (Figure 4) challenge tests. The specificity of all tests was overall high (0.72-0.98). For the swimmers, the mannitol challenge test had the highest sensitivity for diagnosing current asthma (0.57) using extended criteria. The tennis players instead showed a high sensitivity for diagnosing current allergic asthma using the exercise challenge with extended criteria (0.63). In addition, the exercise challenge had a high sensitivity in relation to exacerbation in tennis players, since four of the five tennis players who have had an exacerbation last year had a positive exercise test.

Fifty-four percent of the swimmers and $38 \%$ of the tennis players had a positive skin prick test, while $11 \%$ of the swimmers and $6 \%$ of the tennis players reported asthma symptoms in association with allergens. There were no differences regarding positive skin prick tests and report of asthma symptoms in any of the provocation test results among the swimmers. Among the tennis players, there were no differences in results of the exercise or the mannitol challenge when using the ordinary criteria, but the tennis players with a positive mannitol challenge due to extended criteria had more positive skin prick tests $(p=0.038)$ and reported more asthma symptoms in association with allergens $(p=0.029)$.

No difference was seen in any of the bronchial challenge results between subjects taking inhaled corticosteroids and the subjects not taking inhaled corticosteroids.

\section{Athletes with more training hours}

When investigating subgroups of the elite athletes based on training hours (training $\geq 6$ years and $\geq 15$ hours/week), 73 swimmers (40 males and 33 females) and 24 tennis players (14 males and 10 females) fulfilled the criteria. There was a higher frequency of exercise-induced symptoms $(p<0.0001)$, 


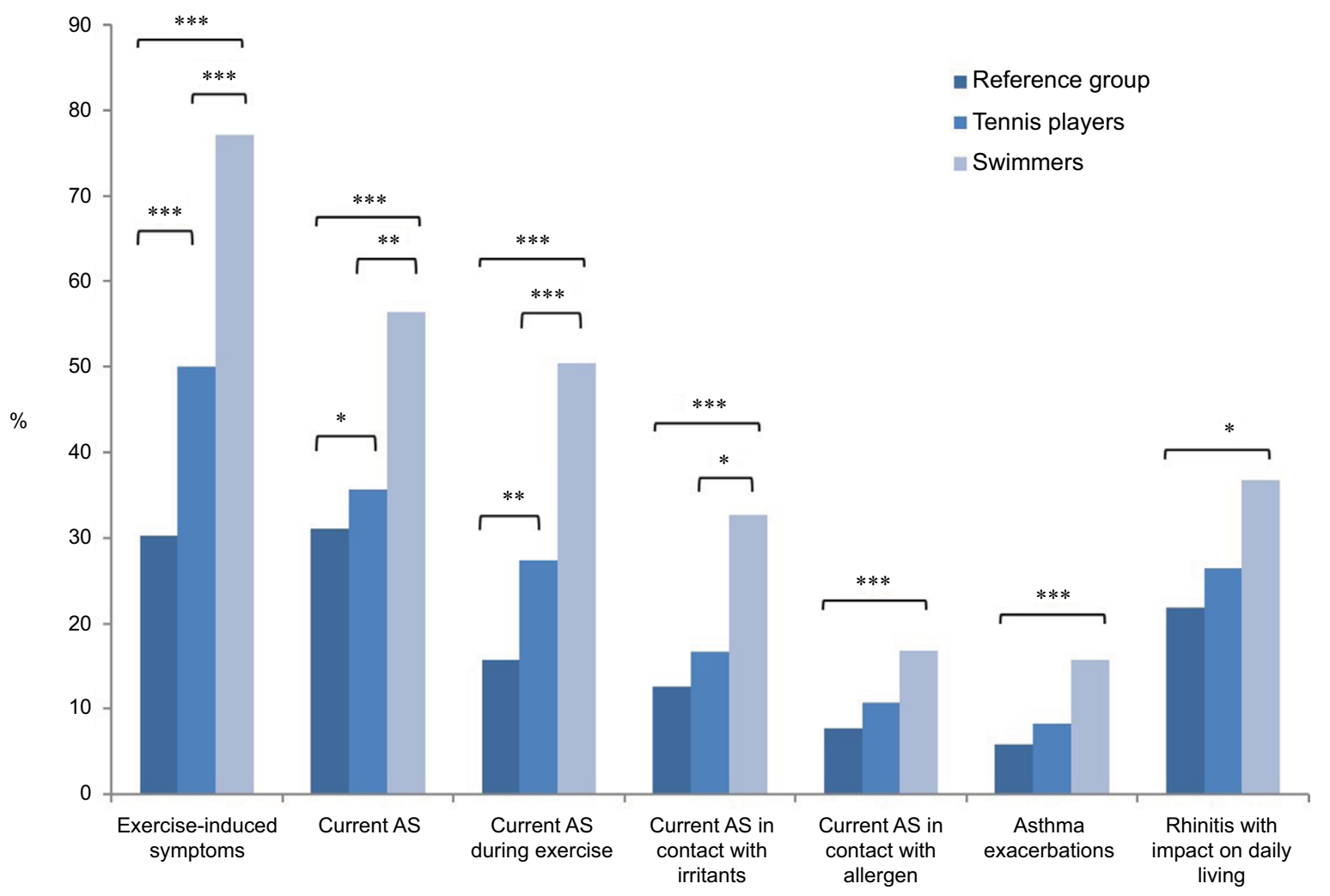

Figure I Respiratory symptoms in swimmers and tennis players in relation to a reference group.

Notes: Asthma exacerbation was defined as emergency visit due to an asthma attack, not able to go to work or school due to asthma and/or substantial temporary change of medication due to deterioration in asthma. ${ }^{*} p<0.05$, ${ }^{*} p<0.01$, ${ }^{* * *} p<0.001$.

Abbreviation: AS, asthma symptoms.

Table 2 Results from mannitol challenge and field exercise challenge in swimmers versus tennis players

\begin{tabular}{|c|c|c|c|c|c|}
\hline & \multicolumn{2}{|c|}{ Swimmers, $n=101$} & \multicolumn{2}{|c|}{ Tennis players, $n=86$} & \multirow[t]{2}{*}{$p$-value* } \\
\hline & $\mathbf{n}$ & $\%$ & $\mathbf{n}$ & $\%$ & \\
\hline Positive mannitol challenge ordinary criteria & $26 / 101$ & 25.7 & $5 / 79$ & 6.3 & 0.001 \\
\hline Positive mannitol challenge extended criteria & $43 / 101$ & 42.6 & $12 / 79$ & 15.2 & $<0.0001$ \\
\hline Positive exercise challenge ordinary criteria & $14 / 97$ & 14.4 & $16 / 67$ & 23.9 & N.S. \\
\hline Positive exercise challenge extended criteria & $24 / 97$ & 24.7 & $19 / 67$ & 28.4 & N.S. \\
\hline Positive reversibility in any test & $47 / 101$ & 46.5 & $21 / 86$ & 25.0 & 0.002 \\
\hline Any positive provocation test ordinary criteria & $33 / 101$ & 32.7 & $20 / 86$ & 23.3 & N.S \\
\hline Any positive provocation test extended criteria & $51 / 101$ & 50.5 & $26 / 86$ & 30.2 & 0.005 \\
\hline
\end{tabular}

Notes: *Statistical comparison between the two groups was conducted using Pearson's chi-square test. n=number of subjects with positive tests/total number of subjects who have undergone the tests. Positive mannitol challenge ordinary criteria defined as a drop in $\mathrm{FEV}_{1} \geq 15 \%$, compared to baseline. Positive exercise challenge ordinary criteria defined as a drop in $\mathrm{FEV}, \geq 10 \%$ from the baseline. Positive reversibility defined as an improvement of $15 \%$ after terbutaline inhalation, compared to maximum fall in $\mathrm{FEV}_{1}$. Positive mannitol challenge extended criteria defined as either a direct fall (ordinary criteria) and/or a positive reversibility. Positive exercise challenge extended criteria defined as either a direct fall (ordinary criteria) and/or a positive reversibility.

Abbreviation: N.S., not significant.

more regular treatment with inhaled corticosteroids ( $p=0.037)$, higher frequency of positive mannitol challenge tests with extended criteria ( $p=0.042)$ and of reversibility $(p=0.038)$ among the swimmers with more training hours, compared to the tennis players with more training hours. This was the same pattern as was seen for all swimmers versus all tennis players.

When investigating the elite groups with more training hours compared with their training partners in the same sport, there was a significantly higher frequency of exercise-induced symptoms ( $p=0.013)$, doctor-diagnosed asthma $(p=0.026)$ and regular use of inhaled corticosteroids $(p=0.042)$ among the athletes with more training hours. However, no significant difference could be found for current asthma with exerciseinduced symptoms $(p=0.062)$ and rhinitis with impact on daily living ( $p=0.069)$. Also, for the provocation tests, no significant increase was found either in the number of subjects with positive mannitol challenge tests with extended criteria $(p=0.066)$ or in reversibility in the mannitol challenge test $(p=0.090)$. 


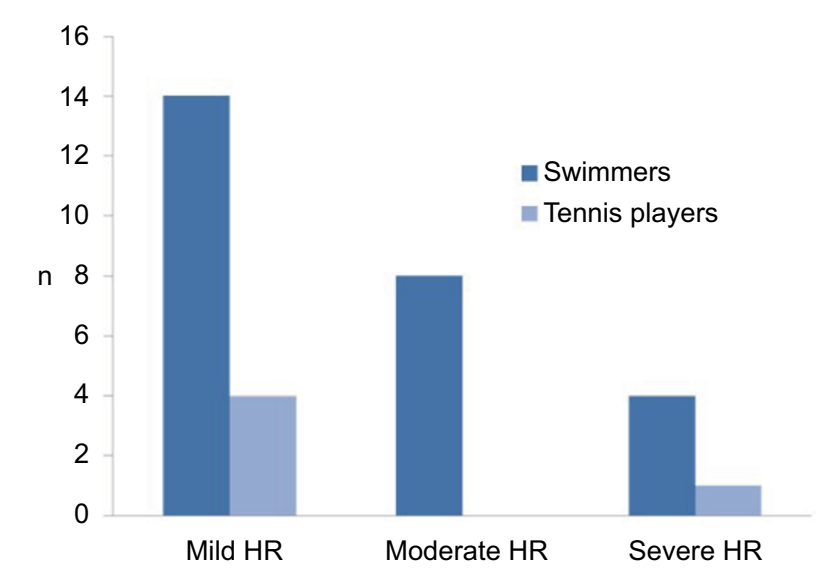

Figure 2 Mannitol reactivity.

Notes: Data presented are the number of swimmers and tennis players positive to mannitol provocation tests (ordinary criteria) grouped into mild (>155 mg), moderate $(>35-\leq 155 \mathrm{mg}$ ) or severe $(\leq 35 \mathrm{mg})$ airway HR.

Abbreviation: HR, hyperreactivity.

Overall, there was a mismatch between reported symptoms of breathing problems related to exercise and outcome of challenge tests, and this pattern differed between swimmers and tennis players (Figure 5). Specifically, most evidently, there was a higher proportion of swimmers with a positive challenge test and asthma symptoms.

\section{Urinary CCI6, $\mathrm{LTE}_{4}$ and II $\beta-\mathrm{PGF}_{2 \alpha}$}

In both swimmers and tennis players, the level of urinary CC16 increased after the exercise challenge test $(p<0.0001$ for both groups). This increase could not be found after the mannitol challenge test. The level of $\mathrm{CC} 16$ after exercise was also significantly higher among the tennis players compared to the swimmers ( $p=0.002$ ), as shown in Figure 6 .

The levels of urinary $11 \beta-\mathrm{PGF}_{2 \alpha}$ increased significantly in both groups after exercise challenge ( $p=0.036$ in swimmers versus $p=0.044$ in tennis players), but remained unchanged after the mannitol challenge test.

Urinary $\mathrm{LTE}_{4}$ was significantly reduced among the swimmers after exercise challenge, as previously shown. ${ }^{10}$ This could not be seen among the tennis players.

A weak correlation between $\mathrm{F}_{\mathrm{E}} \mathrm{NO}$ and the baseline urinary levels of CC16 was seen in both swimmers $(p=0.010$, $r=0.26)$ and tennis players $(p=0.013 r=0.28)$. The tennis players with a positive skin prick test had higher baseline urinary levels of CC16 ( $\mathrm{p}=0.022)$ and $11 \beta-\mathrm{PGF}_{2 \alpha}(p=0.009)$, which could not be seen among the swimmers.

\section{Trichloramine measurement}

The values in the four trichloramine measurements were similar at measurements just above the water surface and at some distance from the poolside during the day of the exercise challenge (330 and $290 \mu \mathrm{g} / \mathrm{m}^{3}$ ) or during a normal training day $\left(320\right.$ and $\left.300 \mu \mathrm{g} / \mathrm{m}^{3}\right)$.

\section{Discussion}

The main finding in this study was that swimmers, compared to the tennis players, had a high frequency of current asthma with or without exercise-induced symptoms, while the frequency of allergen-induced asthma did not differ significantly. We also found that tennis players had a high frequency of current asthma with or without exercise-induced symptoms, compared with the reference group. The swimmers also had a higher frequency of positive mannitol challenge test compared to the tennis players, while the number of positive exercise tests was the same.

\section{Mannitol challenge test}

The swimmers, compared to the tennis players, reported more current asthma symptoms reflected both in more symptoms adjacent to exercise and in contact with irritants, indicating the presence of an increased airway hyperreactivity among the swimmers. This found support in a higher prevalence of positive mannitol challenge tests among the swimmers compared to the tennis players.

Mannitol, as an indirect test, is believed to reflect underlying inflammation and has been shown to correlate well with degree of eosinophilic inflammation measured as $\mathrm{F}_{\mathrm{E}} \mathrm{NO}{ }^{20}$ However, there was no difference in atopy, rhinitis, allergic symptoms toward airborne allergens or $\mathrm{F}_{\mathrm{E}} \mathrm{NO}$ between the swimmers and the tennis players. This further emphasizes that mannitol reactivity in the swimmers most probably has another etiology, that is, membrane dysfunction due to increased stress of the airways, related to their specific sport environment.

\section{Exercise test}

Both the swimmers and the tennis players reported a high prevalence of exercise-induced symptoms. However, in contrast to the mannitol challenge situation, no difference in number of positive exercise challenge tests could be seen between the two groups. One possible explanation might be that we chose to provoke the athletes in the same environment that induces their symptoms, that is, field exercise test. The advantage with field exercise testing is that it is executed in the same environment where the athletes experience most of their respiratory symptoms. Another advantage is that the same type of exercise and their breathing pattern is performed as during their normal training sessions, and 


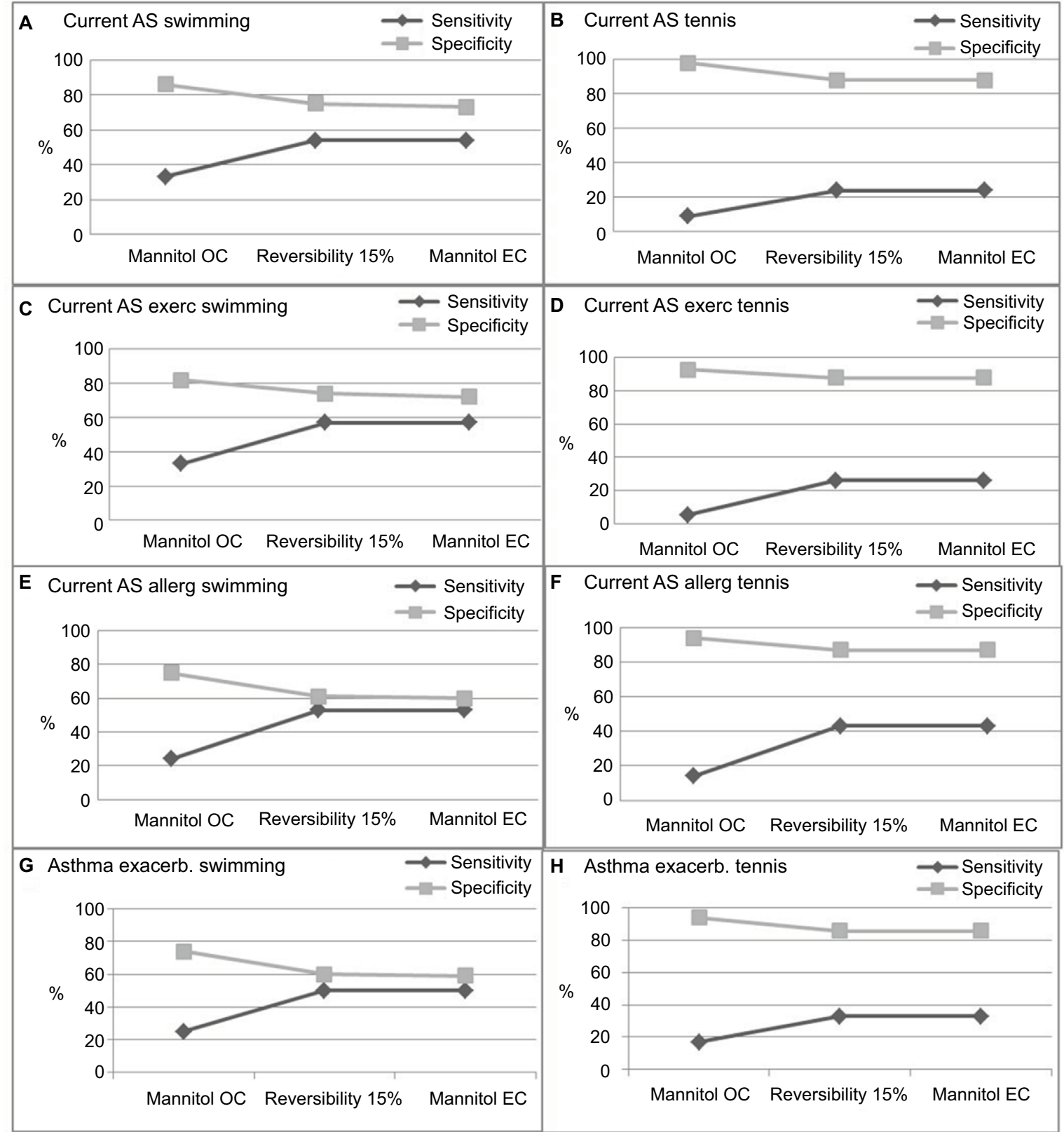

Figure 3 Sensitivity and specificity of mannitol reactivity in relation to respiratory symptoms in swimmers $(\mathbf{A}, \mathbf{C}, \mathbf{E}, \mathbf{G})$ and tennis players $(\mathbf{B}, \mathbf{D}, \mathbf{F}, \mathbf{H})$.

Notes: AS during the last 12 months. OC was defined as a drop in $\mathrm{FEV}$, of $\geq 15 \%$, compared to baseline. Reversibility was defined as an improvement of $15 \%$ after inhalation of I mg terbutaline, compared to the maximum fall in $\mathrm{FEV}_{1}$. EC was defined as either a direct fall $(\mathrm{OC})$ and/or a positive reversibility. Current $\mathrm{AS}(\mathbf{A}$, B)=report of symptoms such as wheezing and/or nocturnal symptoms without respiratory infection and/or asthma medication. Current AS exerc=wheezing, coughing and/or chest tightness adjacent to physical activity (C, D). Current AS allerg=wheezing, coughing and/or chest tightness adjacent to contact with airborne allergens (E, F). Exacerb=emergency room visits, sick leave due to asthma or periods with more accentuated symptoms that required an increase in medication $(\mathbf{G}, \mathbf{H})$.

Abbreviations: AS, asthma symptoms; EC, extended criteria; OC, ordinary criteria.

it is thereby easier to reach a maximal workload. However, a disadvantage is a lack of standardization between sports, and thus, optimal workload could be an issue and has to be checked properly. On the tennis lawn, there was no problem in obtaining a sufficiently high workload and the target work load was easily checked. On the other hand, when performing the test in the pool, it was more difficult to obtain total control of the workload. Another explanation could be that the exercise challenge test in the swimming pool has less of a trigger effect, even if the environment itself induces asthma in a longer perspective, because the test is done in a warmer, humid environment, which we know from experience is less provocative for the bronchial response. ${ }^{21}$

Earlier studies have shown a mismatch between reported symptoms of breathing problems related to exercise and outcome of challenge tests. ${ }^{22-24}$ Contributing factors to this 


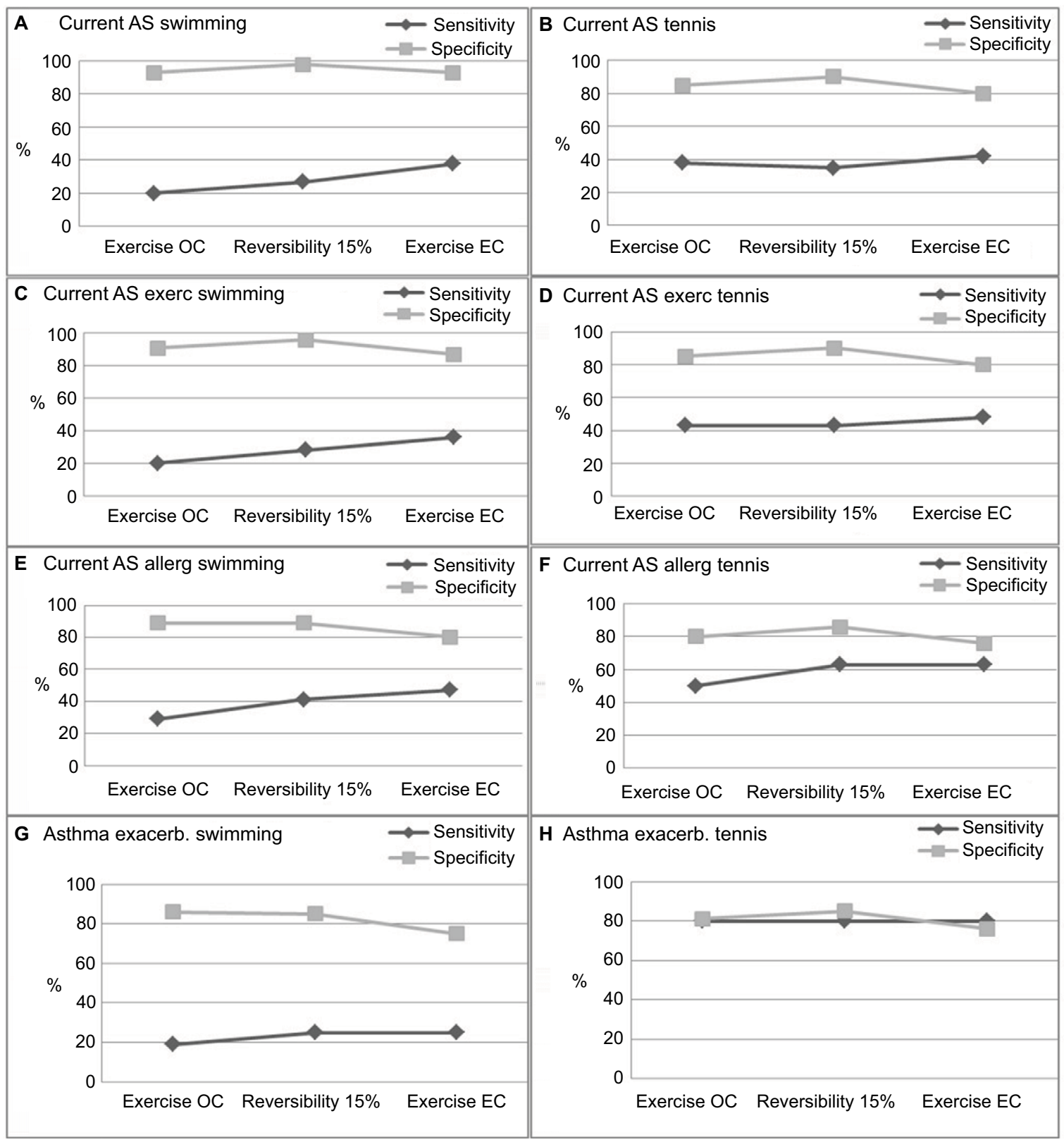

Figure 4 Sensitivity and specificity of exercise challenge response in relation to respiratory symptoms in swimmers $(\mathbf{A}, \mathbf{C}, \mathbf{E}, \mathbf{G})$ and tennis players $(\mathbf{B}, \mathbf{D}, \mathbf{F}, \mathbf{H})$. Notes: AS during the last 12 months. OC was defined as a drop in $\mathrm{FEV}$, of $\geq 15 \%$, compared to baseline. Reversibility was defined as an improvement of $15 \%$ after inhalation of I mg terbutaline, compared to the maximum fall in $\mathrm{FEV}$. EC was defined as either a direct fall $(\mathrm{OC})$ and/or a positive reversibility. Current $\mathrm{AS}(\mathbf{A}, \mathbf{B})=$ report of symptoms such as wheezing and/or nocturnal symptoms without respiratory infection and/or asthma medication. Current AS exerc=wheezing, coughing and/or chest tightness adjacent to physical activity (C, D). Current AS allerg=wheezing, coughing and/or chest tightness adjacent to contact with airborne allergens (E, F). Exacerb=emergency room visits, sick leave due to asthma or periods with more accentuated symptoms that required an increase in medication $(\mathbf{G}, \mathbf{H})$.

Abbreviations: AS, asthma symptoms; EC, extended criteria; OC, ordinary criteria.

could be difficulty to reach sufficient load during the tests due to both poor running technique and the athlete's high level of fitness. In our study, both the exercise and the mannitol challenge showed little overlap with reported exerciseinduced respiratory symptoms. One explanation is that some of the reported exercise-induced symptoms might depend on dynamic hyperinflation..$^{25}$

\section{$\mathrm{CCl} 6$}

An increase of urinary $\mathrm{CC} 16$ was seen after exercise in all subjects, and it was the highest among the tennis players. One explanation could be that the swimmers' ability to secrete/ produce $\mathrm{CC} 16$ could have been disturbed due to constant irritation of the mucosal epithelium caused by a combination of hyperventilation and trichloramines. ${ }^{26}$ The lower increase 


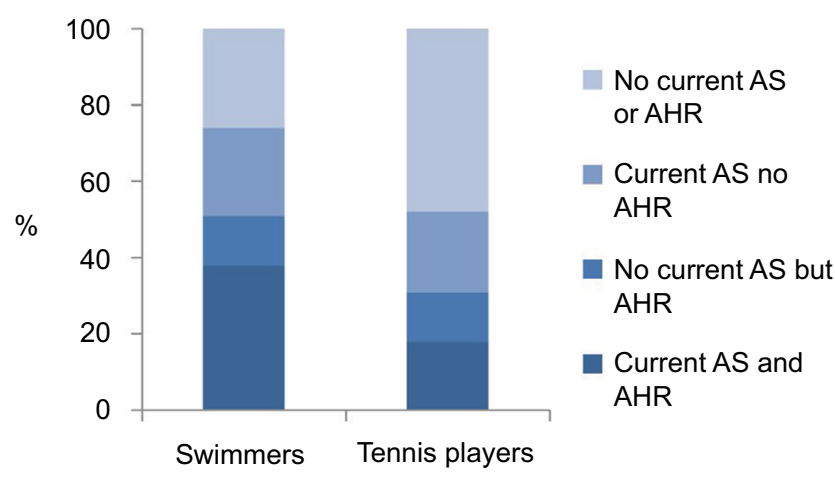

Figure 5 The relation between respiratory symptoms and positive provocation tests among swimmers and tennis players.

Notes: AS were defined as asthma symptoms during the last 12 months. AHR was defined as any positive challenge test (ordinary criteria).

Abbreviations: AHR, airway hyperreactivity; AS, asthma symptoms.

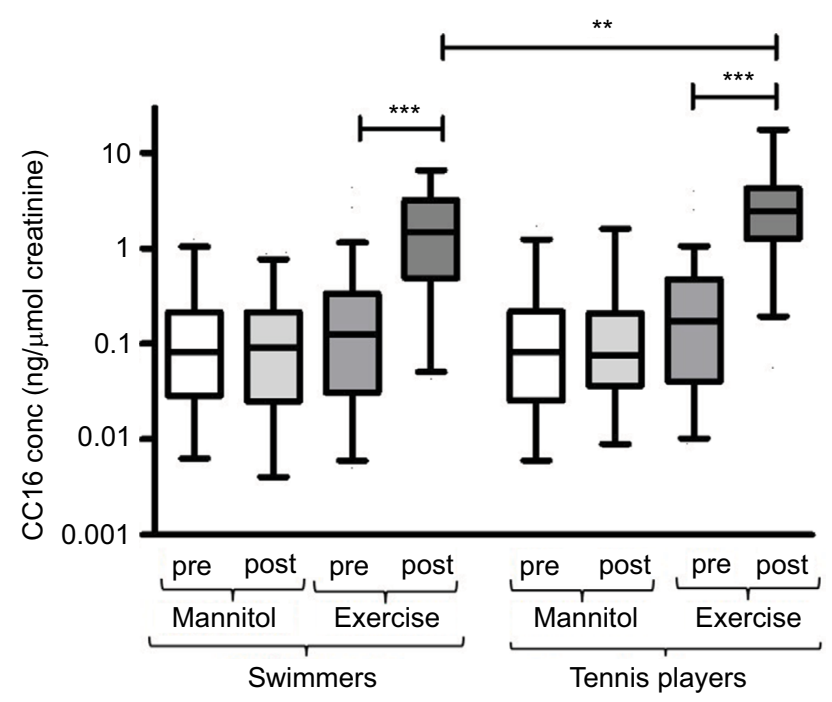

Figure 6 Urinary levels of $\mathrm{CCI} 6$ in swimmers and tennis players before (pre) and I hour after (post) mannitol provocation and/or sport-specific exercise test.

Note: Box plot with whiskers showing 5-95 percentile. ${ }^{* *} p<0.01$, ${ }^{* * *} p<0.001$.

in CC16 after exercise in swimmers compared to the tennis players may, therefore, reflect a disturbance of the protective role of the epithelium. However, the environmental air conditions during provocation have also been shown to influence the $\mathrm{CC} 16$ response; so, the humid, warm air in a swimming arena could be less triggering to the epithelium than the dryer and colder tennis environment. ${ }^{21}$

\section{Asthma symptoms and sport-specific environment}

When comparing the two groups, the swimmers had more training hours per week than the tennis players (Table 1) and they also spent more time in the swimming pool area for social activities. Although both sports are endurance sports and mostly indoors, the environments are quite different - warm and humid air containing chloramine for swimmers, while the tennis players spend their time in indoor tennis courts, often with low temperatures during the winter months and large amounts of airborne particles from the balls, shoes and floor coverings. One tempting explanation for the differences in respiratory symptoms and positive mannitol challenge tests could be an acquired barrier dysfunction in the respiratory epithelium in swimmers as a result of long-term hyperventilation in an unfavorable environment. It has been shown that swimming represents a significant risk for asthma development. ${ }^{6}$ The chlorinated pools and exposure to trichloramines is believed to be an important pathogenetic factor, and there is a clear association with the degree and duration of exposure to chloramines and hyperreactivity and inflammation of the lower airways. ${ }^{4,27}$

Pool workers who are daily exposed to chloramine have lower levels of CC16 in serum, ${ }^{26}$ indicating some degree of epithelial dysfunction. Acute exposure to chlorine in swimming pools has been shown to be linked to an increase in serum levels of $\mathrm{CC} 16,{ }^{28}$ supporting the hypothesis of $\mathrm{CC} 16$ being a protective factor. The levels of $\mathrm{CC} 16$ in serum have been shown to increase post-exercise,$^{10,21}$ which can be explained by an increased hyperventilation-induced stress of the respiratory epithelium. Furthermore, increased exposure of highly chlorinated water induces barrier dysfunction not only in the airways, but also in the skin, seen as an increase in incidence of eczema in exposed children. ${ }^{29}$ The swimmers in this study also reported more eczema, compared to both tennis players and reference controls (Table 1).

Regular checks of indoor environments in all sports facilities are important, especially in indoor swimming pools. In most European countries, no regular checks are conducted of the chloramine content in the air and there are no regulatory standards for control of swimming pools. The World Health Organization recommended in 2006 that $0.5 \mathrm{mg} / \mathrm{m}^{3}$ is suitable as a provisional value for chlorine species, expressed as nitrogen trichloride, in the atmosphere of indoor swimming pools and similar environments. ${ }^{30}$ Since then, further research has shown that chronic damage to the respiratory epithelium occurs at much lower levels of trichloramine. ${ }^{27}$ It is important to optimize the environment of our elite athletes and all others spending time in their sport-specific environment, in order to minimize asthmatic symptoms during long training sessions.

\section{Under- and over-diagnosis of asthma}

Among the athletes, there is a high risk of failing to detect patients with, to our mind, clinically relevant asthma symptoms. In this group, there is a high risk of developing 
asthma, and in our study, we found a trend to misinterpret and underestimate the symptoms both from the trainers and the athletes themselves. The interview revealed that several individuals misinterpreted their exercise-induced symptoms as not being related to bronchial hyperreactivity. An indirect challenge test can be a useful tool to not miss the patients who could benefit from a proper diagnosis and medication. In addition, using extended criteria (including reversibility) gives the test a higher sensitivity without losing much specificity, ${ }^{9}$ and may therefore be more useful as a diagnostic tool.

Since there is also a problem with both over-diagnosis and misdiagnosis of respiratory symptoms, it is important to be aware of the common differential diagnosis. Exercise-induced laryngeal obstruction and dysfunctional breathing can cause asthma-like symptoms ${ }^{31-33}$ and might lead to increased and unwarranted use of asthma medication.

A careful characterization of the asthmatic presentation and identifying the factors that can help us to diagnose better and identify those who may benefit from anti-inflammatory treatment is important. To find these patients, a combination of tests may be needed.

In summary, both swimming and tennis are associated with increased risk of development of asthma, not being related to atopy or degree of allergic sensitization. Swimmers reported more asthma-related symptoms and had higher prevalence of mannitol positive tests. A good assessment algorithm for these patients, using appropriate tests with a high sensitivity to exercise-induced asthma, is required. More research is needed to find appropriate use of the tests and to see if there is a disparity on how different tests function in relation to different sports.

\section{Acknowledgments}

This study was supported by independent grants from Astra-Zeneca, Schering-Plow, MSD, Pharmaxis/Nigaard and Aerocrine.

The authors are truly grateful for the tremendous work done by Caroline Silwer, Ann-Mari Ohrberg, Boel Diwall, Birgitta Wilén, Karin Andersson-Jardby, Carl-Johan Nettrander and Per Romberg. Special thanks go to the swimmers and leaders from MKK, RAN and VNSK. The authors also wish to thank players and trainers from Båstad-Malen TK and National Tennis Secondary School, Fair Play TK, Malmö-Bellevue TK, Skanör-Falsterbo TK, Ystad TK and ATL Lund. Special thanks are also due to all the students in the community of Vellinge who answered the questionnaire in the year 2007.
This study was presented at the 7th World Conference of the International Primary Care Respiratory Group 2014 in Athens, Greece, as an oral conference talk with interim findings. The abstract (OR-005) was published in "Poster Abstracts". Available from: http://www.theipcrg.org/ download/attachments/6455303/7th\%20World\%20Conference $\% 20$ Athens $\% 20 \mathrm{Abstracts}$.pdf?api=v2\&modificationD ate $=1427190149000 \&$ version $=1$.

\section{Author contributions}

KR, ET and LB designed the study and interpreted data. KR collected data and wrote the article draft. ET and LB revised the article critically. All authors contributed toward data analysis, drafting and critically revising the paper and agree to be accountable for all aspects of the work.

\section{Disclosure}

The authors report no conflicts of interest in this work.

\section{References}

1. Randolph CC. Allergic rhinitis and asthma in the athlete. Allergy Asthma Proc. 2006;27(2):104-109.

2. Carlsen KH, Anderson SD, Bjermer L, et al. Exercise-induced asthma, respiratory and allergic disorders in elite athletes: epidemiology, mechanisms and diagnosis: part I of the report from the Joint Task Force of the European Respiratory Society (ERS) and the European Academy of Allergy and Clinical Immunology (EAACI) in cooperation with GA2LEN. Allergy. 2008;63(4):387-403.

3. Dryden DM, Spooner CH, Stickland MK, et al. Exercise-induced bronchoconstriction and asthma. Evid Rep Technol Assess (Full Rep). 2010(189):1-154, v-vi.

4. Helenius I, Rytila P, Sarna S, et al. Effect of continuing or finishing high-level sports on airway inflammation, bronchial hyperresponsiveness, and asthma: a 5-year prospective follow-up study of 42 highly trained swimmers. J Allergy Clin Immunol. 2002;109(6):962-968.

5. Anderson SD, Brannan JD. Methods for "indirect" challenge tests including exercise, eucapnic voluntary hyperpnea, and hypertonic aerosols. Clin Rev Allergy Immunol. 2003;24(1):27-54.

6. Romberg K, Tufvesson E, Bjermer L. Asthma is more prevalent in elite swimming adolescents despite better mental and physical health. Scand J Med Sci Sports. 2012;22(3):362-371.

7. Helenius IJ, Tikkanen HO, Sarna S, Haahtela T. Asthma and increased bronchial responsiveness in elite athletes: atopy and sport event as risk factors. J Allergy Clin Immunol. 1998;101(5):646-652.

8. Langdeau JB, Boulet LP. Prevalence and mechanisms of development of asthma and airway hyperresponsiveness in athletes. Sports Med. 2001;31(8):601-616.

9. Romberg K, Tufvesson E, Bjermer L. Extended diagnostic criteria used for indirect challenge testing in elite asthmatic swimmers. Respir Med. 2012;106(1):15-24.

10. Romberg K, Bjermer L, Tufvesson E. Exercise but not mannitol provocation increases urinary Clara cell protein (CC16) in elite swimmers. Respir Med. 2011;105(1):31-36.

11. Broeckaert F, Bernard A. Clara cell secretory protein (CC16): characteristics and perspectives as lung peripheral biomarker. Clin Exp Allergy. 2000;30(4):469-475.

12. Lakind JS, Holgate ST, Ownby DR, et al. A critical review of the use of Clara cell secretory protein (CC16) as a biomarker of acute or chronic pulmonary effects. Biomarkers. 2007;12(5):445-467. 
13. Haahtela T, Malmberg P, Moreira A. Mechanisms of asthma in Olympic athletes--practical implications. Allergy. 2008;63(6):685-694.

14. Woodcock A, Bleecker ER, Busse WW, et al. Fluticasone furoate: once-daily evening treatment versus twice-daily treatment in moderate asthma. Resp Res. 2011;12:160.

15. Romberg K, Tufvesson E, Bjermer L. Sex differences in asthma in swimmers and tennis players. Ann Allergy Asthma Immunol. 2017;118(3):311-317.

16. Global Initiative for Asthma. Global Strategy for asthma management and prevention. Available from: http://www.ginasthma.org. 2012 Accessed February 15, 2013.

17. Crapo RO, Casaburi R, Coates AL, et al. Guidelines for methacholine and exercise challenge testing-1999. This official statement of the American Thoracic Society was adopted by the ATS Board of Directors, July 1999. Am J Respir Crit Care Med. 2000;161(1):309-329.

18. Quanjer PH, Tammeling GJ, Cotes JE, Pedersen OF, Peslin R, Yernault JC. Lung volumes and forced ventilatory flows. Report working party standardization of lung function tests, European Community for Steel and Coal. Official Statement of the European Respiratory Society. Eur Res J Suppl. 1993;16:5-40.

19. Anderson SD, Brannan J, Spring J, et al. A new method for bronchialprovocation testing in asthmatic subjects using a dry powder of mannitol. Am J Res Crit Care Med. 1997;156(3 Pt 1):758-765.

20. Sverrild A, Malinovschi A, Porsbjerg C, Backer V, Alving K. Predicting airway hyperreactivity to mannitol using exhaled nitric oxide in an unselected sample of adolescents and young adults. Respir Med. 2013;107(1):150-152.

21. Bolger C, Tufvesson E, Anderson SD, et al. Effect of inspired air conditions on exercise-induced bronchoconstriction and urinary CC16 levels in athletes. J Appl Physiol (1985). 2011;111(4):1059-1065.

22. Parsons JP, Kaeding C, Phillips G, Jarjoura D, Wadley G, Mastronarde JG. Prevalence of exercise-induced bronchospasm in a cohort of varsity college athletes. Med Sci Sports Exerc. 2007;39(9):1487-1492.
23. Rundell KW, Im J, Mayers LB, Wilber RL, Szmedra L, Schmitz HR. Self-reported symptoms and exercise-induced asthma in the elite athlete. Med Sci Sports Exerc. 2001;33(2):208-213.

24. Dickinson JW, Whyte GP, McConnell AK, Harries MG. Impact of changes in the IOC-MC asthma criteria: a British perspective. Thorax. 2005;60(8):629-632.

25. Dempsey JA, McKenzie DC, Haverkamp HC, Eldridge MW. Update in the understanding of respiratory limitations to exercise performance in fit, active adults. Chest. 2008;134(3):613-622.

26. Lagerkvist BJ, Bernard A, Blomberg A, et al. Pulmonary epithelial integrity in children: relationship to ambient ozone exposure and swimming pool attendance. Environ Health Perspect. 2004;112(17): 1768-1771.

27. Bernard A, Nickmilder M, Voisin C, Sardella A. Impact of chlorinated swimming pool attendance on the respiratory health of adolescents. Pediatrics. 2009;124(4):1110-1118.

28. Bonetto G, Corradi M, Carraro S, et al. Longitudinal monitoring of lung injury in children after acute chlorine exposure in a swimming pool. Am J Respir Crit Care Med. 2006;174(5):545-549.

29. Chaumont A, Voisin C, Sardella A, Bernard A. Interactions between domestic water hardness, infant swimming and atopy in the development of childhood eczema. Environ Res. 2012;116:52-57.

30. WHO. Guidelines for safe recreational water environments, volume 2, swimming pools and similar environments. WHO Press; 2006.

31. Walsted Nielsen E, Hull JH, Backer V. High prevalence of exerciseinduced laryngeal obstruction in athletes. Med Sci Sports Exerc. 2013;45(11):2030-2035.

32. Roksund OD, Maat RC, Heimdal JH, Olofsson J, Skadberg BT, Halvorsen T. Exercise induced dyspnea in the young. Larynx as the bottleneck of the airways. Respir Med. 2009;103(12):1911-1918.

33. de Groot EP, Duiverman EJ, Brand PL. Dysfunctional breathing in children with asthma: a rare but relevant comorbidity. Eur Respir J. 2013;41(5):1068-1073. 


\section{Supplementary material Subjects}

Between 2008 and 2012, participants were recruited for the study from the elite groups in three of the largest swimming clubs and five tennis clubs, including two tennis high schools (one national), in southern Sweden. Of the 105 swimmers and 87 tennis players who were invited, 101 and 86, respectively, participated in the study.

As a reference group, all the pupils of age 13-20 in the community of Vellinge $(n=1628)$ were enrolled.

\section{Allergy testing}

All subjects were skin prick tested with a panel of airborne allergens, that is, pollen (birch, timothy-grass and mugwort), pets (cat, dog and horse), mold (Cladosporium and Alternaria) and house dust mite (Dermatophagoides pteronyssinus and Dermatophagoides farinae).

\section{Exhaled nitric oxide}

A handheld device (NIOX Mino, Aerocrine, Sweden) was used and the testing procedure was carried out according to the American Thoracic Society and European Respiratory Society recommendations with a exhaled flow rate of $50 \mathrm{~mL} / \mathrm{s}^{1}$

\section{Mannitol challenge test}

Mannitol (Aridol'TM; Pharmaxis ${ }^{\circledR}$, Burnham, Great Britain) was inhaled in incremental doses until a maximal cumulative dose of $635 \mathrm{mg}$ was reached or a drop in $\mathrm{FEV}_{1}$ of $15 \%$ occurred. A flow volume spirometry was performed at baseline and $60 \mathrm{~s}$ after each dose. ${ }^{2}$

\section{Urine analyses}

The urine samples were collected before and 1 hour after the challenge was completed. All males first discarded $100 \mathrm{~mL}$ urine before collection of the urine sample. CC16 was measured using the Human Club Cell Protein ELISA kit (detection limit $0.02 \mathrm{ng} / \mathrm{mL}$ ) from BioVendor (Modrice, Czech Republic) according to the manufacturer's protocol, and leukotriene $\mathrm{E}_{4}$ and 11 $\beta$-prostaglandin- $\mathrm{F}_{2 \alpha}$ were measured using the respective Enzyme Immuno Assay kits (detection limits 25 and 5.5 $\mathrm{pg} / \mathrm{mL}$, respectively) from Cayman Chemical (Ann Arbor, MI, USA). Urinary levels were corrected for the amount of creatinine to compensate for dilution. All samples were run in duplicate with an intrasample variation of $<5 \%$.

\section{Trichloramine measurement}

The trichloramine content of the air (in the swimming pool facilities where the swimmers had their regular training) was measured on two different occasions during the test period, once during the exercise challenge test and another time during the training sessions in the two different swimming pools. Trichloramine was measured within $50 \mathrm{~cm}$ above the water line as well as in the surrounding area in the facility.

\section{References}

1. American Thoracic Society; European Respiratory Society. ATS/ERS recommendations for standardized procedures for online and offline measurement of exhaled lower respiratory nitric oxide and nasal nitric oxide. Am J Respir Crit Care Med. 2005;171(8):912-930.

2. Anderson SD, Brannan JD. Methods for "indirect" challenge tests including exercise, eucapnic voluntary hyperpnea, and hypertonic aerosols. Clin Rev Allergy Immunol. 2003;24(1):27-54.
The Journal of Asthma and Allergy is an international, peer-reviewed open access journal publishing original research, reports, editorials and commentaries on the following topics: Asthma; Pulmonary physiology; Asthma related clinical health; Clinical immunology and the immunological basis of disease; Pharmacological interventions and

\section{Dovepress}

new therapies. This journal is included in PubMed. The manuscript management system is completely online and includes a very quick and fair peer-review system, which is all easy to use. Visit http://www. dovepress.com/testimonials.php to read real quotes from published authors. 